\title{
A Hole Delocalization Strategy: Photoinduced Mixed-Valence MLCT States Featuring Extended Lifetimes
}

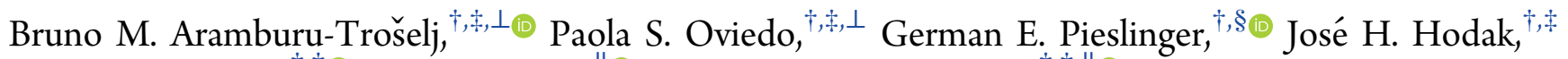
Luis M. Baraldo, ${ }^{* \dagger, \dagger(\uparrow)}$ Dirk M. Guldi, ${ }^{\| \odot}$ and Alejandro Cadranel ${ }^{*}, \dagger,+, \| \odot$

†Universidad de Buenos Aires, Facultad de Ciencias Exactas y Naturales, Departamento de Química Inorgánica, Analítica y Química Física, Pabellón 2, Ciudad Universitaria, C1428EHA, Buenos Aires, Argentina

${ }^{\ddagger}$ CONICET - Universidad de Buenos Aires, Instituto de Química-Física de Materiales, Medio Ambiente y Energía (INQUIMAE), Pabellón 2, Ciudad Universitaria, C1428EHA, Buenos Aires, Argentina

${ }^{\S}$ CONICET - Universidad de Buenos Aires, Instituto de Química y Fisicoquímica Biológicas (IQUIFIB), Junín 956, C1113AAD, Buenos Aires, Argentina

"Department of Chemistry and Pharmacy \& Interdisciplinary Center for Molecular Materials, Friedrich-Alexander-Universität Erlangen-Nürnberg, 91058, Erlangen, Germany

Supporting Information

ABSTRACT: Bimetallic trans- $\left[\mathrm{Ru}^{\mathrm{II}}(\mathrm{tpm})(\mathrm{bpy})(\mu \mathrm{NC})-\right.$ $\left.\mathrm{Ru}^{\mathrm{II}}(\mathrm{L})_{4}(\mathrm{CN})\right]^{2+}$, where bpy is $2,2^{\prime}$-bipyridine, tpm is tris $(1-$ pyrazolyl)methane and $\mathrm{L}=4$-methoxypyridine (MeOpy) or pyridine (py), was examined using ultrafast vis-NIR transient absorption spectroscopy. Of great relevance are the longestlived excited states in the form of strongly coupled photoinduced mixed-valence systems, which exhibit intense photoinduced absorptions in the NIR and are freely tunable by the judicious choice of the coordination spheres of the metallic ions. Using the latter strategy, we succeeded in tailoring the excited state lifetimes of bimetallic complexes and, in turn, achieving significantly longer values relative to related monometallic complexes. Notable is the success in extending the lifetimes, when considering the higher density of vibrational states, as they are expected to facilitate nonradiative ground-state recovery.

\section{INTRODUCTION}

Artificial photosynthesis, a multifaceted approach to foster the conversion of solar energy into chemical energy, is a promising alternative to the widespread use of fossil fuels. ${ }^{1}$ Success in artificial photosynthesis requires, however, the synergy of three key steps: light absorption, charge separation, and multicharge catalysis. ${ }^{2}$ All three steps have been unified in integrated systems by means of designing photocatalytically active electron donor-acceptor ensembles; they evolved as gold standards in the mimicking of natural photosynthesis. ${ }^{3}$ Implicit is a structural modification that targets at the optimization of the individual components as well as the integrated ensembles. An important consideration is that a unidirectional, high quantum-yield funneling of the excited state energy from the Franck-Condon excited states to the charge separated states should commence with the initial photoexcitation. Lifetimes of the correspondingly formed charge separated states are critical, as they determine the time window for the desired redox reactivity at the catalytic sites. A common denominator is the manipulation of electron donor-acceptor interactions in the excited state, that is, the electronic coupling element. For

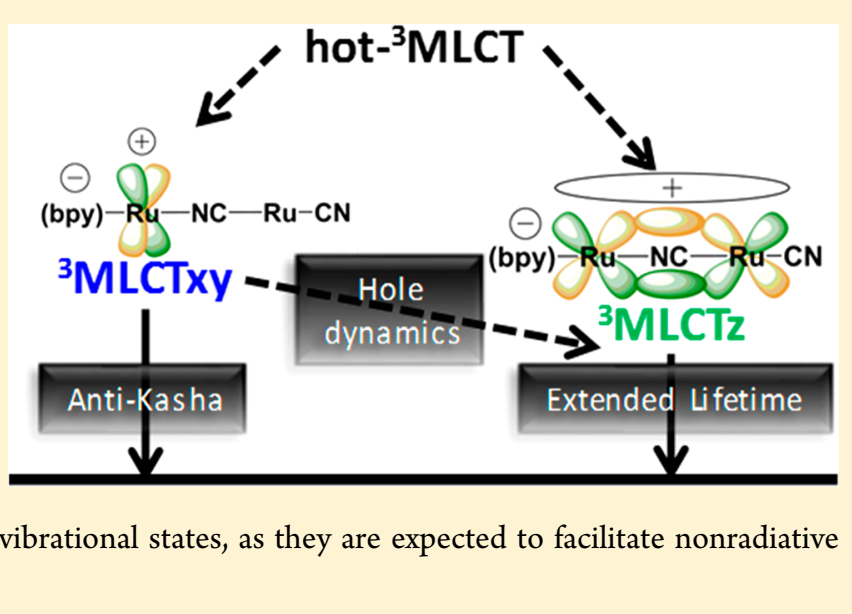

example, low-energy barriers are desirable for a fast excitedstate transformation to afford the charge-separated state, while high-energy barriers are required to slow down the charge recombination.

As far as the ground state is concerned, electrochemical and spectroscopic assays provide an easy access to unravel electron donor-acceptor interactions. In stark contrast, insights into interactions in the excited state are much harder to gather; measuring, for example, excited-state electrochemical properties renders rather difficult. This leads to the grand challenge in the field of electron donor-acceptor systems: a direct comparison between ground and excited states. ${ }^{4}$ To this end, multimetallic chromophores, such as multimetallic ruthenium polypyridines, are ideally suited. Ground-state mixed-valence (GSMV) systems, which are generated by means of their oneelectron oxidation and feature a metal-metal mixed-valence (MV) core, have been extensively studied, ${ }^{5-10}$ including mixed organic-inorganic approaches and supramolecular systems for

Received: May 2, 2019 
solar energy conversion in dye-sensitized solar cells (DSSCs). ${ }^{11-16}$ GSMV moieties are fully comparable with their excited state analogues, that is, photoinduced mixedvalence (PIMV) excited states. PIMV systems bear the same metal-metal MV core as GSMV but carry, in addition, an electron accepting ligand in its one-electron reduced form. For example, we have recently reported on a PIMV state with a $\left\{\left(\mathrm{tpy}^{-}\right) \mathrm{Ru} \mathrm{u}^{\mathrm{II} / \mathrm{III}}-\mathrm{Ru}^{\mathrm{II} / \mathrm{III}}\right\}$ configuration upon photoexcitation of trans- $\left[\mathrm{Ru}^{\mathrm{II}} \text { (tpy) (bpy) }(\mu \mathrm{CN}) \mathrm{Ru}^{\mathrm{II}}(\mathrm{py})_{4} \mathrm{Cl}\right]^{2+}\left(\mathbf{R u R u C l}^{2+}\right)$. The PIMV lifetime was around $1 \mathrm{~ns}$, while a localized $\left\{\left(\mathrm{tpy}^{-}\right) \mathrm{Ru}^{\mathrm{III}}-\right.$ $\mathrm{Ru}^{\mathrm{II}}$ \} excited state persists in that complex for $6 \mathrm{~ns}$. ${ }^{17}$

In the current work, we turn to bimetallic trans- $\left[\mathrm{Ru}^{\mathrm{II}}(\mathrm{tpm})\right.$ (bpy) $\left.(\mu \mathrm{NC}) \mathrm{Ru}^{\mathrm{II}}(\mathrm{L})_{4}(\mathrm{CN})\right]^{2+}$, where bpy is $2,2^{\prime}$-bipyridine, tpm is tris(1-pyrazolyl)methane and $\mathrm{L}=4$-methoxypyridine (MeOpy) or pyridine (py) (Figure 1), and characterize their

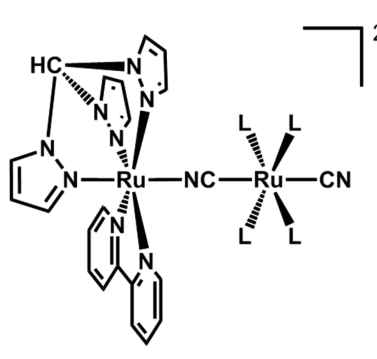

$\operatorname{RuRu}(\mathbf{p y})^{2+}(\mathrm{L}=$ py) $\operatorname{RuRu}(\mathbf{M e O p y})^{2+}(\mathrm{L}=\mathrm{MeOpy})$

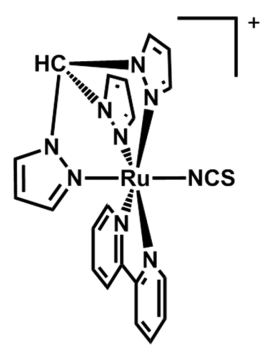

$\operatorname{Ru}(\mathrm{NCS})^{+}$
Figure 1. Structure of the bimetallic $R \mathbf{R u}(\mathrm{py})^{2+}$ and $\mathbf{R u R u}-$ $(\mathrm{MeOpy})^{2+}$ complexes and monometallic $\mathrm{Ru}(\mathrm{NCS})^{+}$reference.

photoexcited states using vis-NIR transient absorption spectroscopy. We demonstrate that the longest-lived (trans$\left.\left[\mathrm{Ru}^{\mathrm{II}}(\mathrm{tpm})(\mathrm{bpy})(\mu \mathrm{NC}) \mathrm{Ru}^{\mathrm{II}}(\mathrm{L})_{4}(\mathrm{CN})\right]^{2+}\right) *$ excited state is a strongly coupled PIMV, whose MV properties rule the overall lifetimes. Our results are groundbreaking, as they corroborate that a judicious choice of the coordination spheres of the metallic ions allows tuning the electronic communication in the ground state and in the excited state. Notable is, for example, the significantly longer excited state lifetimes, which were realized for the bimetallic complexes in comparison with the related monometallic complexes.

\section{RESULTS}

The absorption spectra of $\mathbf{R u R u}(\mathbf{p y})^{2+}$ and $\mathbf{R u R u}(\mathbf{M e O p y})^{2+}$ and their electrochemistry have been previously reported. ${ }^{18,19}$ Their one-electron oxidized species, namely, mixed-valence $\operatorname{RuRu}(\mathrm{MeOpy})^{3+}$ and $\operatorname{RuRu}(\mathrm{py})^{3+}$, have also been characterized. ${ }^{19}$ Figure 2 shows the differential absorption spectra following the one-electron oxidation process of the two complexes, corresponding to $\left\{\mathrm{Ru}(\mathrm{L})_{4}\right\}$ oxidation. In the visible region, bleaching of the MLCT absorptions is attenuated by the simultaneous appearance of LMCT transitions. In the NIR region, the presence of broad bands relates to ground-state intervalence charge transfer (GSIVCT) transitions. Accordingly, $\operatorname{RuRu}(\mathbf{p y})^{3+}$ is classified as a class III ground-state mixed-valence complex. ${ }^{20}$ For $\mathbf{R u R u}(\mathbf{M e O p y})^{3+}$, the significantly weaker transitions infer a different configuration; the hole resides in an orbital which poorly overlaps with the cyanide bridge. Here, mismatched orientations are largely responsible and result in weaker electronic communications. ${ }^{19}$

Bimetallic $\mathrm{RuRu}(\mathrm{py})^{2+}$ and $\mathrm{RuRu}(\mathbf{M e O p y})^{2+}$ are both emissive at room temperature. A series of emission spectra,

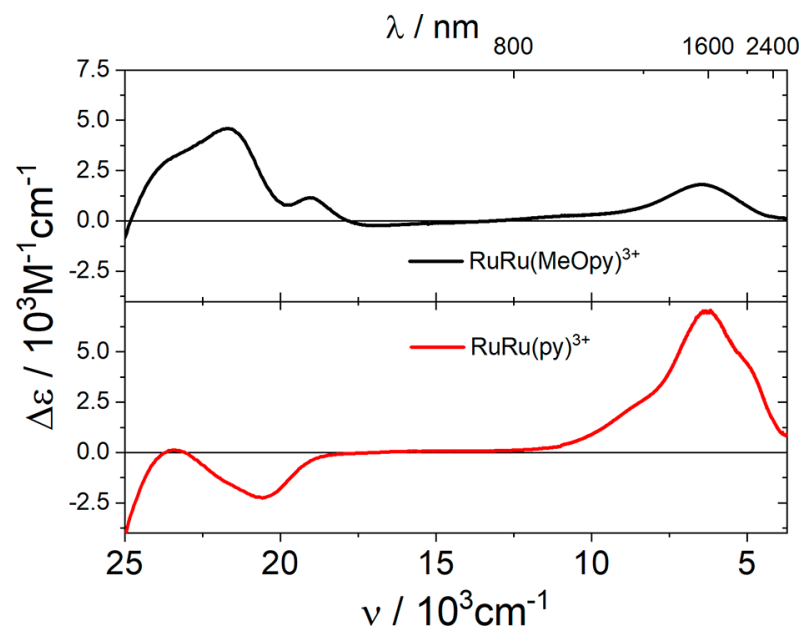

Figure 2. Differential absorption spectra obtained upon the oneelectron oxidation of bimetallic $\operatorname{RuRu}(\mathbf{M e O p y})^{2+}$ and $\mathrm{RuRu}(\mathrm{py})^{2+}$ in acetonitrile at room temperature.

which were recorded upon excitations at different wavelengths, are displayed in Figures S1 and S2. Quite interesting is the dependence of the emission maxima-715 versus $739 \mathrm{~nm}-$ upon the excitation wavelength -387 versus $505 \mathrm{~nm}$. This leads us to postulate the presence of more than one emissive state. In complementary emission lifetime measurements (Figure S3), we derive biexponential decays. This is per se consistent with the involvement of two states, that is, a shortlived and a long-lived state, in the emissive cascade of $\operatorname{RuRu}(\mathrm{py})^{2+}$ and $\operatorname{RuRu}(\mathbf{M e O p y})^{2+}$. Overall, the emission energies as well as the emission lifetimes (Table 1) are in a range typical of MLCT excited states. ${ }^{21}$ In contrast, the emission in the monometallic $\mathbf{R u}(\mathbf{N C S})^{+}$reference stems from a single state regardless of the excitation wavelength. ${ }^{22}$ In other words, the presence of a second metal center seems responsible for an additional emitting state in bimetallic $\mathbf{R u R u}(\mathbf{p y})^{2+}$ and $\operatorname{RuRu}\left(\mathrm{MeOpy}^{2+}\right.$. Despite the higher density of vibrational states that are present in bimetallic $\mathbf{R u R u}(\mathbf{p y})^{2+}$ and $\operatorname{RuRu}(\mathbf{M e O p y})^{2+}$, their emission lifetimes are, however, longer than those in monometallic $\mathbf{R u}(\mathbf{N C S})^{+}$. It is worth noting that linked $\mathrm{Ru}$ polypyridines exhibiting dual emission phenomena have been reported, but in those cases, each of the linked fragments is itself emissive. ${ }^{23-27}$ In contrast, the bimetallic complexes presented in this work bear a nonemitting $\left\{\mathrm{Ru}(\mathrm{L})_{4}\right\}$ site, ${ }^{28}$ which highlights the impact of metal-metal interactions in the excited state properties.

To unveil the nature of the emitting excited states and their dynamics, we performed nanosecond transient absorption spectroscopic (ns-TAS) measurements with $\operatorname{RuRu}(\mathbf{p y})^{2+}$ and $\operatorname{RuRu}(\mathrm{MeOpy})^{2+}$ using 387 and $505 \mathrm{~nm}$ excitation. Following time delays of $15 \mathrm{~ns}$, only single exponential decay kinetics are observed independently of the excitation wavelength. Figure 3 shows representative spectra at $15 \mathrm{~ns}$ time delays. Common to both of them are a total of four features: On one hand, two identical photoinduced transitions evolve at around 19,000 and $13,000 \mathrm{~cm}^{-1}$. On the other hand, two nonidentical photoinduced transitions are noted at around 23,000 and $8500 \mathrm{~cm}^{-1}$. The earlier differs in terms of intensity; the intensity is higher for $\operatorname{RuRu}(\mathrm{MeOpy})^{2+}$ than for $\operatorname{RuRu}(\mathrm{py})^{2+}$ due to contributions from PILMCT absorptions from the MeOpy ligands. ${ }^{28}$ The latter differs in terms of energy and depends on the nature of the complex. For example, it is absent in the monometallic 
Table 1. Photophysical Data for the Bimetallic $\operatorname{RuRu}(\mathrm{MeOpy})^{2+}, \mathrm{RuRu}(\mathrm{py})^{2+}$, and Monometallic $\mathrm{Ru}(\mathrm{NCS})^{+} \mathrm{Reference}$ in DMSO at Room Temperature ${ }^{a}$

\begin{tabular}{|c|c|c|c|c|c|c|}
\hline \multirow[b]{2}{*}{ compound } & \multicolumn{3}{|c|}{$\lambda_{\mathrm{ex}}=387 \mathrm{~nm}$} & \multicolumn{3}{|c|}{$\lambda_{\mathrm{ex}}=505 \mathrm{~nm}$} \\
\hline & $\lambda_{\mathrm{em}} / \mathrm{nm}$ & $\phi_{\mathrm{em}} / 10^{-3}$ & $\tau_{\mathrm{em}} / \mathrm{ns}$ & $\lambda_{\mathrm{em}} / \mathrm{nm}$ & $\phi_{\mathrm{em}} / 10^{-3}$ & $\tau_{\mathrm{em}} / \mathrm{ns}$ \\
\hline $\mathrm{Ru}(\mathrm{NCS})^{+}$ & 740 & 3.1 & 30.5 & 740 & 3.0 & 31.5 \\
\hline $\operatorname{RuRu}(\mathrm{MeOpy})^{2+}$ & 715 & 2.5 & $4.7(0.76),^{b} 51.5(0.24)^{b}$ & 739 & 4.6 & $4.1(0.41),^{c} 51.4(0.59)^{c}$ \\
\hline $\operatorname{RuRu}(\mathrm{py})^{2+}$ & 712 & 1.3 & $4.5(0.84),^{b} 49.4(0.16)^{b}$ & 738 & 4.0 & $3.8(0.69),^{c} 54.4(0.31)^{c}$ \\
\hline
\end{tabular}

${ }^{a}$ Lifetime errors for the biexponential fits for $\mathbf{R u R u}(\mathbf{M e O p y})^{2+}$ and $\mathbf{R u R u}(\mathbf{p y})^{2+}$ are indicated in Table S1. ${ }^{b}$ Excitation at $405 \mathrm{~nm} .{ }^{c}$ Excitation at $515 \mathrm{~nm}$.

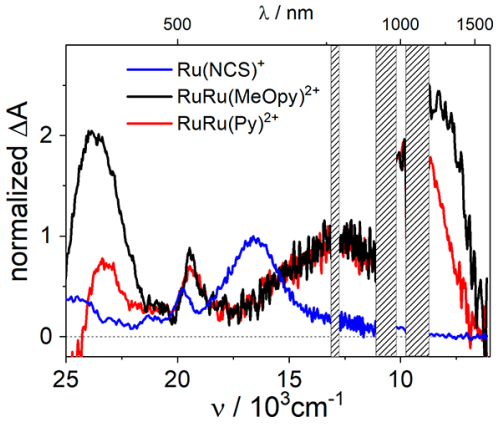

Figure 3. Normalized differential absorption spectra of RuRu$(\mathrm{MeOpy})^{2+}, \mathbf{R u R u}(\mathrm{py})^{2+}$, and $\mathrm{Ru}(\mathrm{NCS})^{+}$at a 15 ns time delay, upon $387 \mathrm{~nm}$ excitation in DMSO at room temperature.

$\mathbf{R u}(\mathrm{NCS})^{+}$reference and, in turn, ascribed to a photoinduced intervalence charge transfer (PIIVCT) (Table 2). In those

Table 2. Electrochemical and Spectroscopic Information Regarding the Electronic Communication in Bimetallic $\operatorname{RuRu}(\mathrm{py})^{2+}, \operatorname{RuRu}\left(\mathrm{MeOpy}^{2+}\right.$, and $\mathrm{RuRuCl}^{2+}$

\begin{tabular}{lccc}
\multicolumn{1}{c}{ compound } & $\Delta(\Delta E)^{a} / \mathrm{V}$ & $\nu(\mathrm{GSIVCT})^{b} / \mathrm{cm}^{-1}$ & $\nu(\mathrm{PIIVCT})^{c} / \mathrm{cm}^{-1}$ \\
$\mathbf{R u R u}(\mathbf{p y})^{2+}$ & $0.41^{d}$ & $6200^{d}$ & 8800 \\
$\mathbf{R u R u}(\mathbf{M e O p y})^{2+}$ & $0.50^{d}$ & $6500^{d}$ & 8100 \\
$\mathbf{R u R u C l}^{2+}$ & $0.87^{e}$ & $10400^{e}$ & $6900^{f}$
\end{tabular}

${ }^{a}$ Differences between $\mathrm{Ru}(\mathrm{III} / \mathrm{II})$ couples within each bimetallic complex, measured in ACN. ${ }^{b}$ Measured in ACN. ${ }^{c}$ Measured in DMSO. ${ }^{d}$ From ref $19 .{ }^{e}$ From ref $29 .{ }^{f}$ From ref 17.

excited states, whose lifetimes are $15 \mathrm{~ns}$ and longer, the holes are located in $\mathrm{d} \pi$ orbitals parallel to the main molecular $z$-axis that contains the cyanide bridge. Thus, we label them ${ }^{3}$ MLCTz. In the corresponding spectra, the MLCT(bpy)centered GS bleaching is absent, in contrast with the vast majority of $\{\mathrm{Ru}($ polypyridine $)\}$ complexes. Here, the negative signal is masked by much stronger photoinduced LMCT (PILMCT) transitions in the same spectral region, in sound agreement with observations on the $\{\mathrm{Ru}(\mathrm{tpm})(\mathrm{bpy})\}$ fragments. $^{22}$

Further examination of the ns-TAS data reveals the nature of another ns-lived state, as suggested by TCSPC experiments. Global target analyses of the transient absorption data (Tables S1 and S2) were performed by means of the kinetic model shown in Figure S7: two coexisting species, which both decay to the GS, as one of them transforms into the other. [Evidence for the process connecting these excited states comes from picosecond experiments; please see below.] In the case of $\operatorname{RuRu}(\mathrm{MeOpy})^{2+}, 387 \mathrm{~nm}$ photoexcitation leads to lifetimes of 0.9 and 51.3 ns. The species-associated difference spectra (SADS) are summarized in Figure 4. Regarding the long-lived

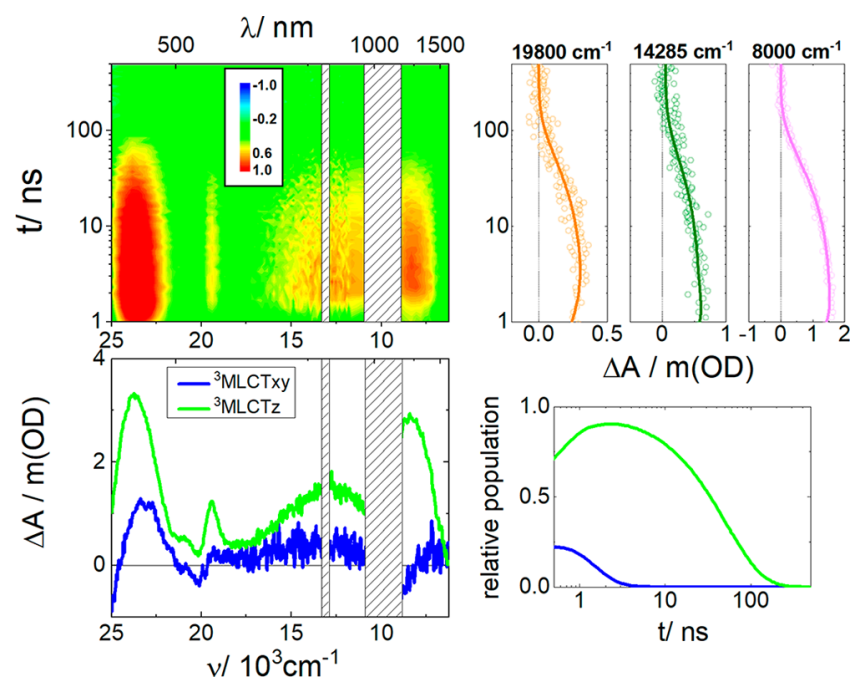

Figure 4. Upper left: Differential absorption 3D map obtained from ns-TAS experiments $\left(\lambda_{\text {exc }}=387 \mathrm{~nm}\right)$ for $\mathbf{R u R u}(\mathbf{M e O p y})^{2+}$ in DMSO at room temperature. Upper right: Time absorption profiles (open circles) and corresponding fittings from target analysis (solid lines). Bottom left: Species-associated differential absorption spectra for ${ }^{3}$ MLCTxy (blue) and ${ }^{3}$ MLCTz (green). Bottom right: concentration evolution over time of the ${ }^{3}$ MLCT excited states.

species $(51.3 \mathrm{~ns})$, its SADS is virtually identical to the differential absorption spectrum at $15 \mathrm{~ns}$ time delay assigned as ${ }^{3}$ MLCTz. The short-lived species $(0.9 \mathrm{~ns})$ lacks any appreciable transition in the NIR region. This leads us to conclude that it must be an excited state without any sizable metal-metal electronic communication. Here, the hole resides in an orbital perpendicular to the main molecular $z$-axis. Consequently, metal-metal overlaps as well as electronic couplings are both insignificant. Its label is ${ }^{3}$ MLCTxy. ${ }^{3}$ MLCTxy and ${ }^{3}$ MLCTz feature similar fingerprints in the $450 \mathrm{~nm}$ region due to the one-electron reduction of the bpy ligand (Figure 4). ${ }^{22}$ Thus, we assign a similar, bpy-centered configuration of the electron for ${ }^{3}$ MLCTxy and ${ }^{3}$ MLCTz. We applied the same kinetic model for $387 \mathrm{~nm}$ excitation of $\operatorname{RuRu}(\mathrm{py})^{2+}$ (Figure S5) and for $505 \mathrm{~nm}$ excitation of

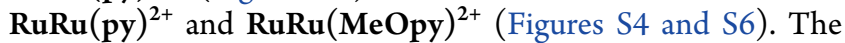
fitting parameters are put together in Table S3.

To shed light onto the population mechanisms of ${ }^{3}$ MLCTxy and ${ }^{3}$ MLCTz, femtosecond transient absorption spectroscopic (fs-TAS) measurements were carried out by using a $387 \mathrm{~nm}$ excitation wavelength. Of great value are the time-dependent absorption changes observed for $\mathbf{R u R u}(\mathbf{M e O p y})^{2+}$ at 19,050 $(525 \mathrm{~nm})$ and $7690 \mathrm{~cm}^{-1}(1300 \mathrm{~nm})$; at least three processes are distinguishable (Figure 5). At, for example, $7690 \mathrm{~cm}^{-1}$, an increase in the population of ${ }^{3} \mathrm{MLCTz}$ takes place during the first nanosecond. Upon the basis of global analyses, which 

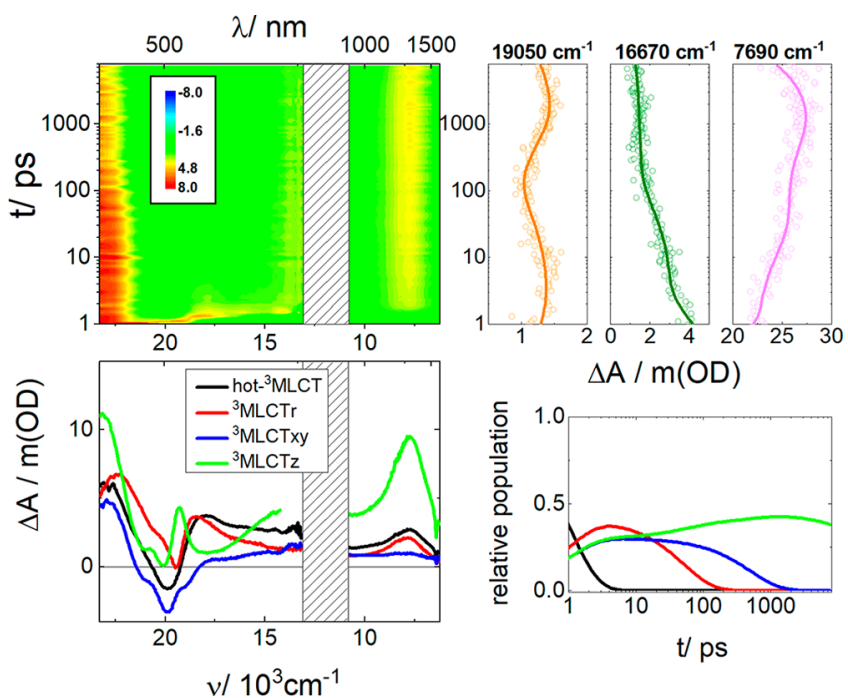

Figure 5. Upper left: Differential absorption 3D map obtained from fs-TAS experiments $\left(\lambda_{\text {exc }}=387 \mathrm{~nm}\right)$ for $\mathbf{R u R u}(\mathbf{M e O p y})^{2+}$ in DMSO at room temperature. Upper right: Time absorption profiles (open circles) and corresponding fittings from target analysis (solid lines). Bottom left: Species-associated differential absorption spectra for hot $-{ }^{3}$ MLCT (black), ${ }^{3}$ MLCTr (red), ${ }^{3}$ MLCTxy (blue), and ${ }^{3}$ MLCTz (green). Bottom right: concentration evolution over time of the ${ }^{3}$ MLCT excited states.

revealed four consecutive processes (Table S4), target analysis using a four-species model (Figure 6) was used to fit the data.

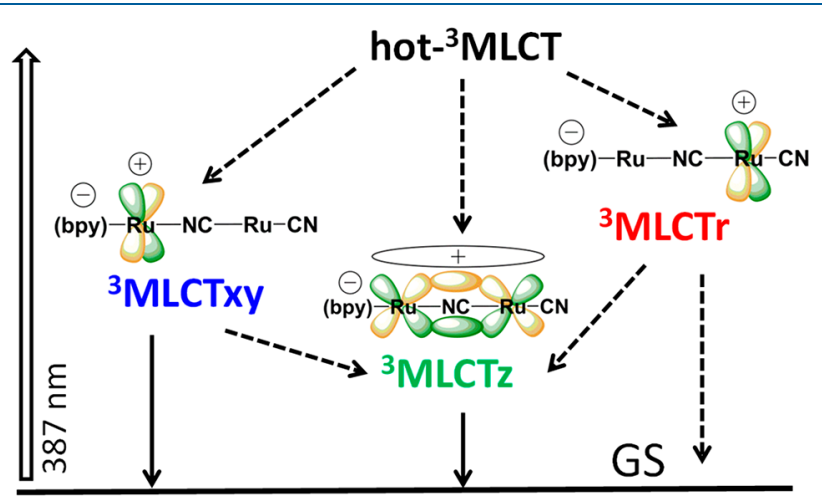

Figure 6. Four-state kinetic model used to fit the picosecond pumpprobe data recorded with bimetallic $\mathbf{R u R u}(\mathbf{M e O p y})^{2+}$ and $\mathbf{R u R u}-$ $(\mathrm{py})^{2+}$ upon $387 \mathrm{~nm}$ excitation.

It includes an initially populated state, which represents a combination of different vibrationally hot- ${ }^{3}$ MLCT excited states, all of which are short-lived. [All of our attempts to individually resolve them failed.] During the first picoseconds, these hot- ${ }^{3}$ MLCTs decay via three parallel branches. The result is the population of three different, coexisting excited states. Two of them, namely, ${ }^{3}$ MLCTxy and ${ }^{3}$ MLCTz, are long-lived, while a third one decays completely within a few tens of picoseconds. Analyses yield a lifetime of $72 \mathrm{ps}$ for the short-lived excited states, while the lifetimes of ${ }^{3}$ MLCTxy and ${ }^{3} \mathrm{MLCTz}$ were kept fixed in the model at 4.7 and $51.3 \mathrm{~ns}$, respectively, in agreement with ns-TAS and TCSPC experiments.

First, the differential absorption spectrum of hot- ${ }^{3}$ MLCT shows a combination of features stemming from the initially populated excited states. Second, the 72 ps lived species gives rise to very weak photoinduced absorbance in the NIR. Hence, we assign it as a state where the hole is, on one hand, perpendicular to the bridge and, on the other hand, centered on the $\mathrm{Ru}$ of the $\left\{\mathrm{Ru}(\mathrm{L})_{4}\right\}$ moiety. Its label is ${ }^{3} \mathrm{MLCTr}$, that is, a $\left\{\mathrm{Ru}^{\mathrm{II}}(\mathrm{tpm})\left(\mathrm{bpy}^{-}\right)(\mu \mathrm{NC}) \mathrm{Ru}^{\mathrm{III}}(\mathrm{L})_{4}(\mathrm{CN})\right\}$ configuration. [This excited state is also involved, for example, as the final state in electronic transitions from the singlet ground state of these complexes calculated by TDDFT methods (transition nos. 4-6 for $\operatorname{RuRu}(\mathbf{M e O p y})^{2+}$ and 6 and 7 for $\operatorname{RuRu}(\mathbf{p y})^{2+}$, Figures S17 and S18, Tables S8 and S9).] Important is the fact that the $\left\{\mathrm{Ru}(\mathrm{L})_{4}\right\}$ fragment is prone to nonradiative deactivation; $^{28}$ it causes the overall short lifetime. We believe that ${ }^{3}$ MLCTr is originated from a fractional, initial population of $\left\{\mathrm{Ru}(\mathrm{L})_{4}\right\}$-centered MLCT states, which are only accessible upon $387 \mathrm{~nm}$ but not $505 \mathrm{~nm}$ light absorption. This is consistent with our experiments using $505 \mathrm{~nm}$ excitation (Figure S8), which leads to similar results with the exception that a reasonable fitting is based on only three species: hot- ${ }^{3}$ MLCT, ${ }^{3}$ MLCTxy, and ${ }^{3}$ MLCTz. [The behavior of $\operatorname{RuRu}(\mathbf{p y})^{2+}$ under 387 and $505 \mathrm{~nm}$ excitation (Figures S9 and $\mathrm{S} 10)$ is analogous to that of $\mathrm{RuRu}(\mathbf{M e O p y})^{2+}$.] Importantly, the mechanism, which we present in Figure 6, is virtually identical to the model employed to fit the decay of the related cyanide-bridged bimetallic complex $\mathbf{R u R u C l}{ }^{2+} .{ }^{17}$ Please note the continuous growth of the PIIVCT throughout the entire fsTAS time scale (trace at $7690 \mathrm{~cm}^{-1}$, Figure 5), which corroborates that ${ }^{3} \mathbf{M L C T r}$ and ${ }^{3}$ MLCTxy transition into ${ }^{3}$ MLCTz. Third, the differential absorption spectra of the 4.7 and 51.3 ns lived species resemble those found in ns-TAS experiments and, as such, further support their assignment as ${ }^{3}$ MLCTxy and ${ }^{3}$ MLCTz. All kinetic parameters extracted from target analyses are collected in Table S5.

\section{DISCUSSION}

Excited State Differential Spectra and Hole Delocalization. The ${ }^{3} \mathbf{M L C T z}$ differential absorption spectra for $\operatorname{RuRu}(\mathrm{py})^{2+}$ and $\mathbf{R u R u}(\mathrm{MeOpy})^{2+}$ are in sound agreement with the findings for the emissive MLCT state in Ru(NCS) ${ }^{+}$. In $\mathbf{R u}(\mathrm{NCS})^{+}$, the emissive state corresponds to an electronic configuration with the hole in a $\mathrm{d}(\mathrm{Ru})$ orbital that points toward the $\mathrm{NCS}^{-}$ligand. In other words, an orientation along the $z$-axis similar to that in $\mathbf{R u R u}(\mathbf{p y})^{2+}$ and $\mathbf{R u R u}(\mathbf{M e O p y})^{2+}$. The spectroscopic signature is a strong photoinduced $\mathrm{d} \pi(\mathrm{Ru})$ $\leftarrow \pi$ (NCS) LMCT absorption at $16,500 \mathrm{~cm}^{-1}(600-610 \mathrm{~nm})$ (Figure 3). ${ }^{22}$ For ${ }^{3} \mathbf{M L C T z}$ in $\mathbf{R u R u}(\mathbf{p y})^{2+}$ and RuRu(MeOpy $)^{2+}$, the lowest energy photoinduced fingerprint is ascribed to a PIIVCT transition. ${ }^{17}$ The latter is centered at $8100 \mathrm{~cm}^{-1}(1230 \mathrm{~nm})$ for $\mathrm{RuRu}(\mathrm{MeOpy})^{4-}$ and $8800 \mathrm{~cm}^{-1}$ $(1150 \mathrm{~nm})$ for $\mathrm{RuRu}(\mathrm{py})^{2+}$. As the donor strength of $\mathrm{L}$ increases, PIIVCT shifts to the red. This indicates that, in contrast to the GS, in the excited state $\{\mathrm{Ru}(\mathrm{bpy})\}, \mathrm{d} \pi$ orbitals lie above those of the $\left\{\mathrm{Ru}(\mathrm{L})_{4}\right\}$ moiety. This is a consequence of the destabilizing effects of the bpy radical anion. As far as the PIIVCT transitions are concerned, the electron donor and acceptor roles are reversed relative to the GSIVCT transitions and now the $\mathrm{Ru}$ in $\{\mathrm{Ru}(\mathrm{tpm})(\mathrm{bpy})\}$ is the acceptor. This behavior has been recently observed in related ruthenium bimetallic complexes. ${ }^{30}$ Common to $\mathbf{R u R u}(\mathbf{p y})^{2+}$ and $\mathbf{R u R u}-$ $(\mathrm{MeOpy})^{2+}$ is an additional ${ }^{3} \mathrm{MLCTz}$ fingerprint at 12,500 $\mathrm{cm}^{-1}(800 \mathrm{~nm})$, which is, however, independent of L. Its origin is similar to that for the PILMCT transition in $\mathbf{R u}(\mathrm{NCS})^{+}$at $16,500 \mathrm{~cm}^{-1}$; it is ascribed to a photoinduced $\mathrm{d} \pi(\mathrm{Ru}) \leftarrow$ 
$\pi(\mathrm{NC})$ LMCT involving the cyanide bridge and $\{\mathrm{Ru}(\mathrm{bpy})\}$ with contributions from photoinduced $\mathrm{d} \pi(\mathrm{Ru}) \leftarrow \pi$ (bpy) LMCT (Tables S7 and S8).

To confirm our spectral assignment of the electronic ${ }^{3}$ MLCTz configuration, we calculated the electronic absorption spectra of the lowest triplet states of $\operatorname{RuRu}(\mathrm{py})^{2+}$ and $\operatorname{RuRu}\left(\mathrm{MeOpy}^{2+}\right.$ by (TD)DFT methods. Notably, the calculations show intense transitions with IVCT character, whose energies match those observed experimentally for both complexes (Figures S12 and S13, Table S6) and whose computed electronic configuration is an accurate description of the ${ }^{3}$ MLCTz excited state. The calculated density of unpaired spins is largely located on the $\{\mathrm{Ru}(\mathrm{tpm})(\mathrm{bpy})\}$ fragment (Figure S14), supporting our interpretation of a photoinduced acceptor and leading to a higher degree of delocalization for $\operatorname{RuRu}(\mathbf{M e O p y})^{2+}$. The Mulliken spin densities on the $\{\mathrm{Ru}(\mathrm{bpy})\}$ and $\left\{\mathrm{Ru}(\mathrm{L})_{4}\right\}$ metallic ions are 0.71 and 0.18 , respectively, in $\mathrm{RuRu}(\mathbf{M e O p y})^{2+}$, and 0.79 and 0.13, respectively in $\mathbf{R u R u}(\mathrm{py})^{2+}$. Interestingly, ${ }^{3} \mathbf{M L C T z}$ is more localized in $\operatorname{RuRu}(\mathbf{M e O p y})^{2+}$ and $\operatorname{RuRu}(\mathbf{p y})^{2+}$ than in $\mathrm{RuRuCl}^{2+}$. For $\mathrm{RuRuCl}^{2+}$, a delocalized configuration with Mulliken spin densities of 0.50 and 0.47 and a lower PIIVCT energy were calculated. ${ }^{17}$ As a matter of fact, the PIIVCT energy was much lower than the values obtained here. In other words, a shift to lower energies goes hand-in-hand with a higher delocalized character as, for example, in the GSIVCTs.

From the lack of photoinduced absorptions in the NIR for ${ }^{3}$ MLCTxy differential absorption spectra, we conclude that the metal-metal electronic coupling in these excited states is weak. Additionally, the $12,500 \mathrm{~cm}^{-1}$ fingerprint is absent. The visible range of this differential spectrum is governed by a bleaching at $22,200-20,000 \mathrm{~cm}^{-1}(450-500 \mathrm{~nm})$, where the MLCT $\{\mathrm{Ru}(\mathrm{bpy})\}$ absorptions dominate the ground state. ${ }^{19}$ A very similar differential absorption spectrum was gathered for an excited state with the hole repelled from the $z$-axis in Ru(NCS) ${ }^{+22}$ Together, these observations are in line with the proposed $\left\{\mathrm{Ru}^{\mathrm{III}}(\mathrm{tpm})\left(\mathrm{bpy}^{-}\right)(\mu \mathrm{NC}) \mathrm{Ru}^{\mathrm{II}}(\mathrm{L})_{4}(\mathrm{CN})\right\}$ configuration for this state.

Kinetic Model and Excited State Lifetimes. Notably, our kinetic model describes the excited state dynamics of $\operatorname{RuRu}(\mathrm{py})^{2+}$ and $\operatorname{RuRu}(\mathbf{M e O p y})^{2+}$ very well. A very similar model was also employed to analyze the excited state decay of the closely related complex $\mathbf{R u R u C l} \mathbf{l}^{2+}$. ${ }^{17}$ Thus, it seems widely applicable in the field of multimetallic chromophoric coordination compounds.

${ }^{3}$ MLCTxy and ${ }^{3}$ MLCTz coexist on the nanosecond time scale. However, in contrast to $\mathrm{RuRuCl}^{2+},{ }^{3} \mathrm{MLCTz}$ is the longest lived excited state for $\mathbf{R u R u}(\mathbf{M e O p y})^{2+}$ and $\mathbf{R u R u}-$ $(\mathrm{py})^{2+}$. We believe that three factors contribute to these findings: First, like electron delocalization in extended aromatic ligands, ${ }^{31}$ hole delocalization in PIMV complexes places the excited state energy surface nested with the ground state, yielding longer lifetimes for ${ }^{3}$ MLCTz. Second, the absence of labile bonds, such as $\mathrm{Ru}-\mathrm{Cl}$, avoids fast relaxations to the ground state, as it happens when comparing $\{\mathrm{Ru}-$ $\left.(\text { bpy })_{2}(\mathrm{CN})_{2}\right\}$ against $\left\{\mathrm{Ru}(\mathrm{bpy})_{2} \mathrm{Cl}_{2}\right\}$ complexes. ${ }^{32}$ Additionally, energy differences between the different ${ }^{3} \mathrm{MLCT}$ states may result in different rates for the population of upper ${ }^{3} \mathrm{MC}$ states. All of the aforementioned is linked to lifetimes, which are for $\operatorname{RuRu}(\mathbf{M e O p y})^{2+}$ and $\mathbf{R u R u}(\mathrm{py})^{2+}$ longer than that for the $\mathbf{R u}(\mathrm{NCS})^{+}$model, despite their larger sizes. In short, an alternative strategy to extend MLCT excited state lifetimes, which is based on hole delocalization rather than electron delocalization, is potentially useful in the design of novel chromophore-catalyst assemblies.

The PIIVCT rise across the NIR throughout the fs-TAS time scale is clear evidence for a ${ }^{3} \mathrm{MLCTxy}$-to- ${ }^{3} \mathrm{MLCTz}$ transition. For bimetallic $\operatorname{RuRu}(\mathbf{M e O p y})^{2+}$ and $\operatorname{RuRu}(\mathrm{py})^{2+}$, this process is based on a hole reconfiguration. It resembles that observed for the monometallic $\mathbf{R u}(\mathbf{N C S})^{+}$reference, where an intermediate ${ }^{3} \mathrm{MLCT}$ state transforms into the emissive ${ }^{3}$ MLCT in 375 ps. The kinetic barrier associated with this process is seemingly higher for $\operatorname{RuRu}(\mathbf{M e O p y})^{2+}$ and $\operatorname{RuRu}(\mathrm{py})^{2+}$ than for $\mathbf{R u}(\mathbf{N C S})^{+}$. Since orbital mixing in the lowest ${ }^{3} \mathrm{MLCT}$ involves a bigger fragment in the former $(\{\mathrm{Ru}-$ $\mathrm{NC}-\mathrm{Ru}\})$ than in the latter ( $\{\mathrm{Ru}-\mathrm{NCS}\})$, we hypothesize that more vibronic degrees of freedom involved in the hole reconfiguration in the bimetallic $\mathbf{R u R u}(\mathbf{M e O p y})^{2+}$ and $\mathbf{R u R u}-$ $(\mathrm{py})^{2+}$ versus the monometallic $\mathbf{R u}(\mathbf{N C S})^{+}$are likely responsible for the higher kinetic barrier. This is counterintuitive, considering that a higher density of vibrational states in the former is expected to facilitate nonradiative ground-state recovery. Overall, however, a multitude of bond angles and bond distances need to be rearranged. Modulation of this barrier evolves as a control over the relative population of ${ }^{3}$ MLCTxy and ${ }^{3}$ MLCTz; tunable symmetries and spatial localizations are expected to result in diverse reactivities. Further experiments to investigate these barriers are being carried out in our laboratories.

\section{EXPERIMENTAL SECTION}

Materials and Methods. $\mathrm{RuRu}(\mathrm{MeOpy})^{2+}$ and $\mathrm{RuRu}(\mathrm{py})^{2+}$ were prepared according to published procedures. ${ }^{19}$ Anhydrous DMSO was provided by Sigma-Aldrich and used as supplied.

Excitation and emission spectra were recorded in a PTIQuantaMaster or a Cary Eclipse spectrofluorimeter. Quantum yields were measured in argon-saturated solutions using $\left[\mathrm{Ru}(\mathrm{bpy})_{3}\right]^{2+}(\varphi=$ $0.095^{33}$ in $\mathrm{ACN}$ at $25^{\circ} \mathrm{C}$ ). Fluorescence lifetimes were determined through the time-correlated single photon counting (TCSPC) technique using a set of in-lab built laser LEDs $(7 \mathrm{MHz}$, fwhm $=$ $50 \mathrm{ps}, \lambda_{\text {exc }}=405$ and $515 \mathrm{~nm}, 70 \mathrm{pJ}$ per pulse) with a SPAD detection system from Micro Photon Devices controlled by a TimeHarp 260 board from PicoQuant. Photolysis studies were performed following a previously reported procedure. ${ }^{34}$ All measurements were conducted under an argon atmosphere. The time profiles were recorded at 700 $\mathrm{nm}$. Ultrafast transient absorption (TA) experiments were conducted using an amplified Ti:sapphire fs laser system (Clark MXR CPA2101 and $2110,1 \mathrm{kHz}$, fwhm $=150 \mathrm{fs}, \lambda_{\text {exc }}=387$ and $505 \mathrm{~nm}, 200-300 \mathrm{~nJ}$ per pulse) with TA pump/probe Helios and EOS detection systems from Ultrafast Systems. For the picosecond to nanosecond experiments (Helios), white light was generated focusing a fraction of the fundamental $775 \mathrm{~nm}$ output onto a $2 \mathrm{~mm}$ sapphire disk ( 430-760 $\mathrm{nm})$ or a $1 \mathrm{~cm}$ sapphire disk $(\sim 800-1600 \mathrm{~nm})$. A magic angle configuration was employed to avoid rotational dynamics. Excitation pulses of 387 and $505 \mathrm{~nm}$ wavelength were generated by a NOPA. Bandpass filters with \pm 5 or $\pm 10 \mathrm{~nm}$ were used to ensure a low spectral width and to exclude $775 \mathrm{~nm}$ photons. For the nanosecond to microsecond experiments (EOS), white light $(\sim 370$ to $>1600 \mathrm{~nm})$ was generated by a built-in photonic crystal fiber supercontinuum laser source with a fundamental of $1064 \mathrm{~nm}$ at $2 \mathrm{kHz}$ output frequency and a pulse width of approximately $1 \mathrm{~ns}$. All measurements were conducted in a $2 \mathrm{~mm}$ quartz cuvette under an argon atmosphere. To analyze transient absorption data, we use a suggested procedure. ${ }^{35}$ We start with global analysis, using an all-sequential decay model, to determine the number of decaying species that participate in the decay cascade. However, this does not necessarily yield differential spectra with true physicochemical meaning. Afterward, a target analysis is applied, using specific target models that result in species associated spectra with true physicochemical meaning. Obtained data 
were treated by global and target analyses using the R-package TIMP and GloTarAn. ${ }^{33-37}$

Theoretical Calculations. Density functional theory (DFT) computations were employed to fully optimize geometries of the compound in DMSO, without symmetry constraints. Geometries of the singlet ground state were optimized and serve as the starting point for the optimization of the lowest-lying triplet state species. The calculations were done with the Gaussian 09 package, ${ }^{38}$ at the B3LYP level of theory using restricted and unrestricted approximations of the Kohn-Sham equations, depending on the system multiplicity. ${ }^{39}$ In all cases, we employed the effective core potential basis set LanL2DZ, which proved to be suitable for geometry predictions in coordination compounds containing metals of the second row of the transition elements in the Periodic Table. All of the calculations were performed using an UltraFine grid. Solvation effects were accounted for using the most recent implementation of the implicit IEF-PCM solvation model. ${ }^{40-42}$ We used tight convergence criteria in the geometry optimizations and default settings for IR calculations. All optimized structures were confirmed as minima by analyzing the harmonic vibrational frequencies. ${ }^{43}$ Vertical electronic excitation energies and intensities were evaluated using the time-dependent DFT ((TD)DFT $)^{44,45}$ approach with the Gaussian 09 package, ${ }^{38}$ without symmetry constraints. GaussSum $2.2 .6^{46}$ software was used to perform spectral simulation, to extract spectral data and molecular orbital information, and to obtain the electron density difference maps (EDDMs). The graphical visualizations were generated by GaussView5.0.8; ${ }^{47}$ i.e., the isovalues were drawn at 0.004 (EDDM), 0.04 (Kohn-Sham MOs), or 0.004 (spin-density calculations).

\section{CONCLUSIONS}

We have shown that, for both bimetallic complexes explored, two excited states with different configurations, ${ }^{3}$ MLCTxy and ${ }^{3}$ MLCTz, coexist in the nanosecond time scale. While the first one is mainly localized on a single metallic ion, the latter presents substantial hole delocalization over the $\mathrm{d} \pi$ orbitals of the two Ru ions. Such coexistence could be of wide occurrence in multimetallic chromophoric coordination compounds. In ${ }^{3}$ MLCTz, electronic communication can be synthetically tailored, providing a new strategy to extend excited state lifetimes. Given the different expected reactivities for ${ }^{3}$ MLCTxy and ${ }^{3} \mathrm{MLCTz}$, tuning the relative population of these excited states would be a valuable tool to exert chemical control over the reactivity of the excited states.

\section{ASSOCIATED CONTENT}

\section{S Supporting Information}

The Supporting Information is available free of charge on the ACS Publications website at DOI: 10.1021/acs.inorgchem.9b01254.

Absorption/emission spectra, TCSPC measurements, additional figures and tables (PDF)

\section{AUTHOR INFORMATION}

\section{Corresponding Authors}

*E-mail: baraldo@qi.fcen.uba.ar.

*E-mail: acadranel@qi.fcen.uba.ar.

ORCID $\odot$

Bruno M. Aramburu-Trošelj: 0000-0001-7150-4458

German E. Pieslinger: 0000-0003-1334-5211

Luis M. Baraldo: 0000-0003-0666-5540

Dirk M. Guldi: 0000-0002-3960-1765

Alejandro Cadranel: 0000-0002-6597-4397

\section{Author Contributions}

${ }^{\perp}$ B.M.A.-T. and P.S.O. have equally contributed to this work.

\section{Notes}

The authors declare no competing financial interest.

\section{ACKNOWLEDGMENTS}

This work was supported by grants from the University of Buenos Aires (UBACyT 20020130100534BA), CONICET (PIP 112-20150100394CO), and ANPCyT (PICT 2013 00069). P.S.O. gratefully acknowledges a doctoral fellowship from CONICET and funding from ANPCyT to visit FAU Erlangen-Nürnberg, and A.C., a postdoctoral grant from DAAD-ALEARG. G.E.P. thanks Prof. Dr. Adrián Roitberg for selflessly sharing his knowledge and DAAD for personal funding. G.E.P., J.H.H., L.M.B., and A.C. are members of the research staff of CONICET, and B.M.A.-T. is a postdoctoral fellow of the same institution. B.M.A.-T. and A.C. are ALN associates.

\section{REFERENCES}

(1) Faunce, T.; Styring, S.; Wasielewski, M. R.; Brudvig, G. W.; Rutherford, A. W.; Messinger, J.; Lee, A. F.; Hill, C. L.; deGroot, H.; Fontecave, M.; et al. Artificial Photosynthesis as a Frontier Technology for Energy Sustainability. Energy Environ. Sci. 2013, 6 (4), 1074

(2) Đokić, M.; Soo, H. S. Artificial Photosynthesis by Light Absorption, Charge Separation, and Multielectron Catalysis. Chem. Commun. 2018, 54, 6554-6572.

(3) El-Khouly, M. E.; El-Mohsnawy, E.; Fukuzumi, S. Solar Energy Conversion: From Natural to Artificial Photosynthesis. J. Photochem. Photobiol., C 2017, 31, 36-83.

(4) Endicott, J. F.; Chen, Y. J. Electronic Coupling between Metal Ions in Cyanide-Bridged Ground State and Excited State Mixed Valence Complexes. Coord. Chem. Rev. 2013, 257 (9-10), 16761698.

(5) Hankache, J.; Wenger, O. S. Organic Mixed Valence. Chem. Rev. 2011, 111 (8), 5138-5178.

(6) Launay, J. P. Long-Distance Intervalence Electron Transfer. Chem. Soc. Rev. 2001, 30 (6), 386-397.

(7) D’Alessandro, D. M.; Keene, F. R. Current Trends and Future Challenges in the Experimental, Theoretical and Computational Analysis of Intervalence Charge Transfer (IVCT) Transitions. Chem. Soc. Rev. 2006, 35 (5), 424-440.

(8) Demadis, K. D.; Hartshorn, C. M.; Meyer, T. J. The Localizedto-Delocalized Transition in Mixed-Valence Chemistry. Chem. Rev. 2001, 101 (9), 2655-2685.

(9) Winter, R. F. Half-Wave Potential Splittings $\Delta$ E $1 / 2$ as a Measure of Electronic Coupling in Mixed-Valent Systems: Triumphs and Defeats. Organometallics 2014, 33 (18), 4517-4536.

(10) Oviedo, P. S.; Pieslinger, G. E.; Cadranel, A.; Baraldo, L. M. Exploring the Localized to Delocalized Transition in Non-Symmetric Bimetallic Ruthenium Polypyridines. Dalt. Trans. 2017, 46 (45), 15757-15768.

(11) Bomben, P. G.; Gordon, T. J.; Schott, E.; Berlinguette, C. P. A Trisheteroleptic Cyclometalated RuII Sensitizer That Enables High Power Output in a Dye-Sensitized Solar Cell. Angew. Chem., Int. Ed. 2011, 50 (45), 10682-10685.

(12) Robson, K. C. D.; Koivisto, B. D.; Yella, A.; Sporinova, B.; Nazeeruddin, M. K.; Baumgartner, T.; Grätzel, M.; Berlinguette, C. P. Design and Development of Functionalized Cyclometalated Ruthenium Chromophores for Light-Harvesting Applications. Inorg. Chem. 2011, 50 (12), 5494-5508.

(13) Robson, K. C. D.; Sporinova, B.; Koivisto, B. D.; Schott, E.; Brown, D. G.; Berlinguette, C. P. Systematic Modulation of a Bichromic Cyclometalated Ruthenium(II) Scaffold Bearing a RedoxActive Triphenylamine Constituent. Inorg. Chem. 2011, 50 (13), 6019-6028. 
(14) Hu, K.; Robson, K. C. D.; Johansson, P. G.; Berlinguette, C. P.; Meyer, G. J. Intramolecular Hole Transfer at Sensitized $\mathrm{TiO} 2$ Interfaces. J. Am. Chem. Soc. 2012, 134 (20), 8352-8355.

(15) Yao, C. J.; Zheng, R. H.; Shi, Q.; Zhong, Y. W.; Yao, J. 1,4Benzene-Bridged Covalent Hybrid of Triarylamine and Cyclometalated Ruthenium: A New Type of Organic-Inorganic MixedValent System. Chem. Commun. 2012, 48 (45), 5680-5682.

(16) Kreitner, C.; Mengel, A. K. C.; Lee, T. K.; Cho, W.; Char, K.; Kang, Y. S.; Heinze, K. Strongly Coupled Cyclometalated Ruthenium Triarylamine Chromophores as Sensitizers for DSSCs. Chem. - Eur. J. 2016, 22 (26), 8915-8928.

(17) Oviedo, P. S.; Pieslinger, G. E.; Baraldo, L. M.; Cadranel, A.; Guldi, D. M. Coexistence of MLCT Excited States of Different Symmetry upon Photoexcitation of a Single Molecular Species. J. Phys. Chem. C 2019, 123 (6), 3285-3291.

(18) Cadranel, A.; Aramburu Trošelj, B. M.; Yamazaki, S.; Alborés, P.; Kleiman, V. D.; Baraldo, L. M. Emissive Cyanide-Bridged Bimetallic Compounds as Building Blocks for Polymeric Antennae. Dalt. Trans. 2013, 42 (48), 16723-16732.

(19) Pieslinger, G. E.; Aramburu-Trošelj, B. M.; Cadranel, A.; Baraldo, L. M. Influence of the Electronic Configuration in the Properties of $\mathrm{d}(6)-\mathrm{d}(5)$ Mixed-Valence Complexes. Inorg. Chem. 2014, 53, 8221-8229.

(20) Robin, M. B.; Day, P. MIXED VALENCE CHEMISTRY-A SURVEY AND CLASSIFICATION. Adv. Inorg. Chem. Radiochem. 1968, 10, 247-422.

(21) Juris, A.; Balzani, V.; Barigeletti, F.; Campagna, S.; Belser, P.; von Zelewsky, A. $\mathrm{Ru}(\mathrm{II})$ Polypyridine Complexes: Photophysics, Photochemistry, Electrochemistry Adn Chemiluminescence. Coord. Chem. Rev. 1988, 84, 85-277.

(22) Cadranel, A.; Oviedo, P.; Pieslinger, G. E.; Yamazak, S.; Kleiman, V. D.; Baraldo, L. M.; Guldi, D. M. Trapping Intermediate MLCT States in Low-Symmetry $\{\mathrm{Ru}(\mathrm{Bpy})\}$ Complexes. Chem. Sci. 2017, 8, 7434-7442.

(23) Glazer, E. C.; Magde, D.; Tor, Y. Dual Emission from a Family of Conjugated Dinuclear RuII Complexes. J. Am. Chem. Soc. 2005, 127 (12), 4190-4192.

(24) Kreitner, C.; Grabolle, M.; Resch-Genger, U.; Heinze, K. Dual Emission and Excited-State Mixed-Valence in a Quasi-Symmetric Dinuclear Ru-Ru Complex. Inorg. Chem. 2014, 53 (24), 1294712961.

(25) Kreitner, C.; Heinze, K. The Photochemistry of Mono- and Dinuclear Cyclometalated Bis(Tridentate)Ruthenium(II) Complexes: Dual Excited State Deactivation and Dual Emission. Dalt. Trans. 2016, 45, 5640-5658.

(26) Glazer, E. C.; Magde, D.; Tor, Y. Ruthenium Complexes That Break the Rules: Structural Features Controlling Dual Emission. J. Am. Chem. Soc. 2007, 129 (27), 8544-8551.

(27) Magde, D.; Magde, M. D.; Glazer, E. C. So-Called "Dual Emission" for 3MLCT Luminescence in Ruthenium Complex Ions: What Is Really Happening? Coord. Chem. Rev. 2016, 306, 447-467.

(28) Cadranel, A.; Pieslinger, G. E.; Tongying, P.; Kuno, M. K.; Baraldo, L. M.; Hodak, J. H. Spectroscopic Signatures of Ligand Field States in $\{$ RuII(Imine) $\}$ Complexes. Dalt. Trans. 2016, 45 (13), 5464-5475.

(29) Cadranel, A.; Tate, J. E.; Oviedo, P. S.; Yamazaki, S.; Hodak, J. H.; Baraldo, L. M.; Kleiman, V. D. Distant Ultrafast Energy Transfer in a Trimetallic $\{\mathrm{Ru}-\mathrm{Ru}-\mathrm{Cr}\}$ Complex Facilitated by Hole Delocalization. Phys. Chem. Chem. Phys. 2017, 19 (4), 2882-2893.

(30) Aramburu Trošelj, B. M.; Oviedo, P. S.; Ramírez-Wierzbicki, I.; Baraldo, L. M.; Cadranel, A. Inversion of Donor-Acceptor Roles in Photoinduced Intervalence Charge Transfers. Chem. Commun. 2019, $55,7659-7662$.

(31) Damrauer, N. H.; Boussie, T. R.; Devenney, M.; Mccusker, J. K.; April, R. V. Effects of Intraligand Electron Delocalization, Steric Tuning, and Excited-State Vibronic Coupling on the Photophysics of Aryl-Substituted Bipyridyl Complexes of Ru (II). J. Am. Chem. Soc. 1997, 119 (35), 8253-8268.
(32) Nazeeruddin, M. K.; Kay, A.; Miiller, E.; Liska, P.; Vlachopoulos, N.; Gratzel, M. Conversion of Light to Electricity by Cis-X2Bis(2,2'-Bipyridyl-4,4'-Dicarboxylate)Ruthenium(11) ChargeTransfer Sensitizers (X $=\mathrm{C1} 1-, \mathrm{Br}-$, I-, CN-, and Cis-XSCN-) on Nanocrystalline Ti02 Electrodes. J. Am. Chem. Soc. 1993, 115 (14), $6382-6390$

(33) Yamamoto, Y.; Tamaki, Y.; Yui, T.; Koike, K.; Ishitani, O. New Light-Harvesting Molecular Systems Constructed with a $\mathrm{Ru}$ (II) Complex and a Linear-Shaped Re (I) Oligomer. J. Am. Chem. Soc. 2010, 132 (33), 11743-11752.

(34) Marcolongo, J. P.; Schmidt, J.; Levin, N.; Slep, L. D. A Chemometric Approach for Determining the Reaction Quantum Yields in Consecutive Photochemical Processes. Phys. Chem. Chem. Phys. 2017, 19 (32), 21373-21381.

(35) Van Stokkum, I. H. M.; Larsen, D. S.; Van Grondelle, R. Global and Target Analysis of Time-Resolved Spectra. Biochim. Biophys. Acta, Bioenerg. 2004, 1657 (2-3), 82-104.

(36) Snellenburg, J. J.; Laptenok, S. P.; Seger, R.; Mullen, K. M.; van Stokkum, I. H. M. Glotaran: A Java -Based Graphical User Interface for the R Package TIMP. J. Stat. Softw. 2012, DOI: 10.18637/ jss.v049.i03.

(37) Mullen, K. M.; van Stokkum, I. H. M. TIMP: An R Package for Modeling Multi-Way Spectroscopic Measurements. J. Stat. Softw. 2007, 18 (3), 46

(38) Frisch, M. J.; Trucks, G. W.; Schlegel, H. B.; Scuseria, G. E.; Robb, M. A.; Cheeseman, J. R.; Scalmani, G.; Barone, V.; Mennucci, B.; Petersson, G. A.; et al. Gaussian 09, revision D.01; Gaussian, Inc.: Wallingford, CT, 2013.

(39) Szabo, A.; Ostlund, N. S. Modern Quantum Chemistry: Introduction to Advanced Electronic Structure Theory; McGraw-Hill Education: New York, 1996.

(40) Scalmani, G.; Frisch, M. J. Continuous Surface Charge Polarizable Continuum Models of Solvation. I. General Formalism. J. Chem. Phys. 2010, 132 (11), 114110.

(41) Tomasi, J.; Mennucci, B.; Cammi, R. Quantum Mechanical Continuum Solvation Models. Chem. Rev. 2005, 105 (8), 2999-3094.

(42) Miertuš, S.; Scrocco, E.; Tomasi, J.; Miertuš, S.; Scrocco, E.; Tomasi, J. Electrostatic Interaction Of A Solute With A Continuum. A Direct Utilization Of $\mathrm{Ab}$ Initio Molecular Potentials For The Prevision Of Solvent Effects. Chem. Phys. 1981, 55 (1), 117-129.

(43) Schlegel, H. B. Optimization of Equilibrium Geometries and Transition Structures. J. Comput. Chem. 1982, 3 (2), 214-218.

(44) Petit, L.; Maldivi, P.; Adamo, C. Predictions of Optical Excitations in Transition-Metal Complexes with Time DependentDensity Functional Theory: Influence of Basis Sets. J. Chem. Theory Comput. 2005, 1 (5), 953-962.

(45) Stratmann, R. E.; Scuseria, G. E.; Frisch, M. J. An Efficient Implementation of Time-Dependent Density-Functional Theory for the Calculation of Excitation Energies of Large Molecules. J. Chem. Phys. 1998, 109 (19), 8218-8224.

(46) O’Boyle, N. M.; Tenderholt, A. L.; Langner, K. M. Cclib: A Library for Package-Independent Computational Chemistry Algorithms. J. Comput. Chem. 2008, 29 (5), 839-845.

(47) Dennington, R.; Keith, T.; Millam, J. GaussView, version 5; Semichem Inc.: Shawnee Mission, KS, 2009. 